\title{
IMPACTS OF BIMODAL INSTRUCTION THAT ASSOCIATES PHONEMIC SKILLS WITH MUSIC SKILLS ON PRESCHOOLERS PHONEMIC AWARENESS
}

\author{
Johanne Belmon, Magali Noyer-Martin, \& Sandra Jhean-Larose \\ ERCAE, Orléans University (France)
}

\begin{abstract}
Phonemic awareness has been observed to be a strong predictor of later reading skills (Ziegler, 2018, Ecalle \& Magnan, 2015). Increasingly, recent studies specialized in orthophonic reeducation show that phonemic awareness can be trained by musical programs (Patscheke, Degé \& Schwarzer, 2016). Few studies, according to the scientific literature, have developed a combined method that associates musical skills and phonemic awareness at the same time, for French speakers. In contrast with training programs, the originality of the present study consists in ecological conditions which fit in with teaching practices.

If phonemic awareness and music skills share common information treatment mechanisms, the effect of a combined learning method should enhance phonemic awareness skills compared to a traditional one. The present experiment evaluated the effect of bimodal instruction that associates phonemic awareness with musical education on phonemic skills. Fifty-three children from four different classes $(25$ girls, 28 boys) aged 5 years old and 8 months (3.36) were assigned to two groups. We compared bimodal instruction to phonemic awareness (experimental group, $\mathrm{n}=33$ ) to a traditional one (control group, $\mathrm{n}=20$ ). Each learning conditions lasted 7 weeks and included two 30 minutes learning sessions per week.

Children prerequisites to phonemic awareness have been measured with rhyme recognition and syllable suppression tasks. Four tasks divided in 12 items (3 increasing levels of difficulty) measured phonemic skills in recognition and suppression (initial, final). The same test was applied before and after the learning session. Each item's answers were rated from 0 to 1. Results analyses (ANOVA) show better improvement on epiphonemic skills in posttest from the experimental group that from the control one $(\mathrm{F}(1.52)=14.440, \mathrm{p}=.00038)$. These positive results may be explained by a multi-sensory and multimodal instruction.
\end{abstract}

Keywords: Phonemic awareness, music instruction, bimodal pedagogic sequence.

\section{Introduction}

Learning to read in an alphabetic system is based on the alphabetic principle. This includes the ability to identify graphemes (smaller writing language units) and associating them to corresponding sounds, phonemes (smaller oral language units). Then, sounds are linked up in order to form syllables, words (Piquard-Kipffer \& Sprenger-Charolles, 2013). Reading skills development needs a priori the conscious identification and manipulation of phonemes, namely phonemic awareness. Phonemic awareness has been observed to be a strong predictor of later reading skills (Ziegler, 2018, Ecalle \& Magnan, 2015). However, this ability does not develop naturally in childhood and needs a specific learning (Goswami \& East, 2000). The scientific literature demonstrates that, multi sensori learning (visual, auditory, haptic) shows better improvement on phonemic awareness learning (Labat, Magnan \& Ecalle 2011). Thus, as a teaching domain, musical instruction shares several features with phonemic awareness such as information treatment mechanisms and common functional basis (Platel, 2003). Perceptive music skills are closely linked to phonemic skills (Bolduc, Montésinos-Gelet \& Boisvert, 2014). In that sense increasingly, recent studies specialized in orthophonic reeducation show that phonemic awareness could be trained by musical programs (Patscheke, Degé \& Schwarzer, 2016). Few studies, according to the scientific literature, have developed a combined method that associates musical skills and phonemic awareness at the same time, for French speakers. In contrast with training programs, the originality of the present study consists in ecological conditions which fit in with teaching practices.

\section{Objectives}

If phonemic awareness and music skills share common information treatment mechanisms, the effect of a combined learning method should enhance phonemic awareness skills compared to an unimodal one. The present experiment evaluated the effect of bimodal instruction that associates phonemic awareness with musical instruction on preschoolers phonemic skills. 


\section{Method}

\subsection{Participants}

53preschoolers (25 girls, 28 boys) from three different Center France schools aged 5 (5.8, SD 3.6) participated to this experiment. They were assigned to two groups: the bimodal instruction (experimental group, $\mathrm{n}=33$ ) and the unimodal one (control group, $\mathrm{n}=20$ ).

\subsection{Learning programs}

Each learning programs lasted 7 weeks and included two 30 minutes learning sessions per week (14 learning sessions). The preschoolers received sessions in their usual classroom in groups of 6 to 8 children. The programs implemented by the teachers for their pupils were guided by those designed by the authors.

3.2.1. Bimodal program: Music and phonemic skills. The originality of the present program is to combine music skills and phonemic skills at the same time. This program was created by the authors, based on corresponding skills between music and language established by Sloboda (2005). A typical learning session included a first task based on listening skills (identify, locate phonemes and sounds), and a second task based on manipulation skills (suppression, permutation, encoding phonemes and sounds). For instance, children listened to a song, then guessed which sounds they heard as well as recognized which phonemes were present in it. Other typical sessions involved encoding sounds and phonemes to create short songs.

3.2.2. Unimodal program: Single phonemic skills. The control group program was based on "Access Phono" method (Dorner, 2013), a phonological skills program specifically designed to teach phonological awareness. This program has been chosen because of its widespread in French classes. It contained phoneme recognition exercises and encoding exercises. Typical sessions contained listening tasks that involved phoneme recognition in words, then encoding tasks. For example, children closed their eyes, listened to a word and guessed if the target phoneme is present, then they were asked to write the phoneme on a slate.

3.2.3. Learning programs comparison. Both programs involved epiphonemic and metaphonemic skills by the use of listening and encoding exercises. The aim differences consisted in teaching materials and curriculum. The bimodal program associated visual and auditory aids (letters, music scores and songs) while unimodal one only used auditory aids (phonemes, sounds). Finally, the bimodal program involved phonemes that have been worked on throughout each learning session compared to the unimodal program which worked on phonemes separately.

\subsection{Measures}

Children prerequisites to phonemic awareness have been measured with rhyme recognition and syllable suppression tasks. Then, phonemic awareness was assessed by a test designed by the authors adapted for previous test (Doyen, Noyer-Martin, 2016). It consisted to four tasks divided in 12 items (3 increasing levels of difficulty) measuring phonemic skills in recognition (identify the intruder in four words lists) and suppression (remove a phoneme from a word) in initial, then the final phoneme position in words. The same test was immediately applied before and after the learning session. Each item answers foresaw scores ranging from 0 to 1 .

\section{Results}

Analysis of the variance (ANOVA) was performed with time factors (T1 vs. T2) and instruction factors (bimodal vs. unimodal). First, the scores on large units prerequisites (rhyme, syllable) revealed no group difference $(\mathrm{F}(2.50)=1.4504), \mathrm{p}=.24416)$. Three way interaction (time*difficulty levels*instruction) did not reveal significant difference $(\mathrm{F}(2.104)=1.1957, \mathrm{p}=.30660)$ but showed that both group improved their epiphonemic skills. At the pretest, epiphonemical awareness scores did not significantly differ between experimental and control group $(\mathrm{F}(1)=2.902013, \mathrm{p}=.094439)$. Finally, results show better improvement on epiphonemic skills in posttest from the experimental group that from the control one $(\mathrm{F}(1.52)=14.440, \mathrm{p}=.00038)$ (Figure 1$)$. 
Figure 1. Epiphonemical awareness scores at pre-test and post-test in the experimental group and the control group.

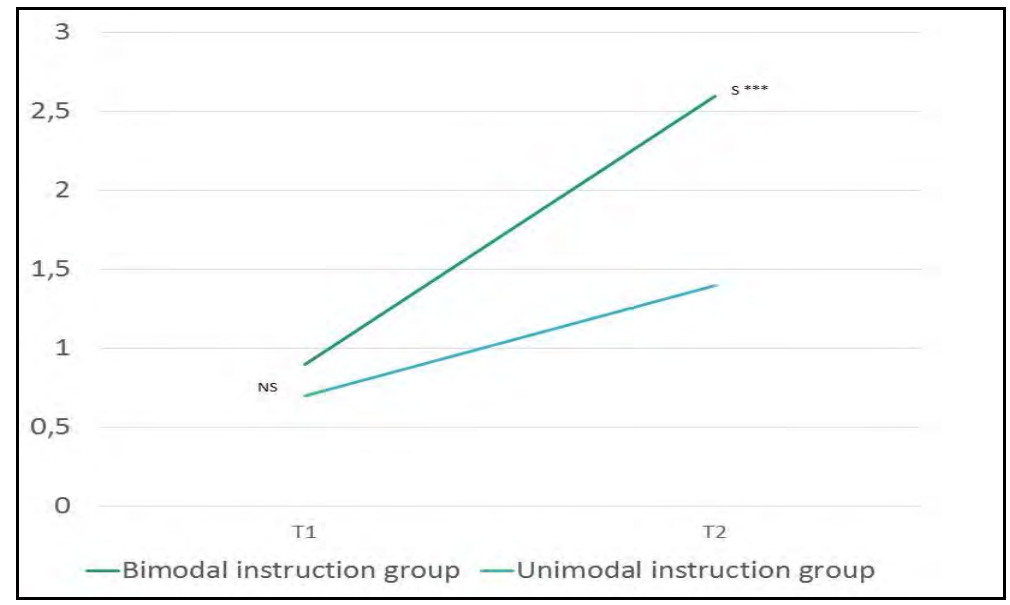

\section{Discussion / conclusion}

The purpose of the present experiment was to assess the effect of bimodal learning program which associates phonemical and musical skills in preschoolers. Thus, this effect was compared to an unimodal phonemical skills program. The pretest results show that there are no significant differences between the experimental group and the control one. This demonstrates that the group assignment did not impact the results. Both groups improved in phonemic awareness. The design showed an enhancing effect of combined method which gathered music and phonemic skills at the same time on phonemic awareness, especially on epiphonemic abilities. These positive results may be explained by a multi-sensory and multimodal instruction (Ecalle \& al, 2011). Indeed, musical instruction enabled preschoolers to developed phonemic skills by the use of multi-sensory tools (songs, instruments, musical scores). In accordance with previous findings of Bolduc (2014), the design shows that perceptive musical skills are linked to a phonological one even on small units. In a next study, assess bimodal instruction effects in longitudinal study may underlying and identifying predictors to later phonemic skills in combined instruction.

\section{References}

Bolduc, J., Montésinos-Gelet, I., \& Boisvert, S. (2014). Perceptions musicales et conscience phonologique: recherche auprès d'enfants francophones d'âge préscolaire. Psychologie française, 59(3), 247-255.

Dorner, C. Vers la phono grande section. Acces éditions, 2013.

Doyen, A. L., \& Noyer-Martin, M. (2016). Effets d'un entrainement perceptivo-moteur et aux orthographes approchées sur les compétences scripturales à 5 ans. In Symposium international sur la litéracie à l'école/International Symposium for Educational Literacy (SILE/ISEL) (2015: Jouvence, Québec) (pp. 80-102). Les Éditions de l'Université de Sherbrooke (ÉDUS).

Ecalle, J., \& Magnan, A. (2015). L'apprentissage de la lecture et ses difficultés-2e éd. Dunod.

Goswami, U., \& East, M. (2000). Rhyme and analogy in beginning reading: Conceptual and methodological issues. Applied Psycholinguistics, 21(1), 63-93.

Labat, H., Magnan, A., \& Ecalle, J. (2011). Effet d'une exploration multisensorielle séquentielle orientée sur le développement de la compréhension du principe alphabétique chez les enfants de 5 ans faibles connaisseurs de lettres. LAnnee psychologique, 111(4), 641-671.

Patscheke, H., Degé, F., \& Schwarzer, G. (2016). The effects of training in music and phonological skills on phonological awareness in 4-to 6-year-old children of immigrant families. Frontiers in psychology, 7, 1647.

Piquard-Kipffer, A., \& Sprenger-Charolles, L. (2013). Early predictors of future reading skills: A follow-up of French-speaking children from the beginning of kindergarten to the end of the second grade (age 5 to 8). LAnnee psychologique, 113(4), 491-521.

Platel, H., Baron, J. C., Desgranges, B., Bernard, F., \& Eustache, F. (2003). Semantic and episodic memory of music are subserved by distinct neural networks. Neuroimage, 20(1), 244-256.

Sloboda, J. (2005). Exploring musical mind: cognition, emotion, ability, function. Oxford University Press.

Ziegler, J. C. (2018). Différences inter-linguistiques dans l'apprentissage de la lecture. Langue française, (3), 35-49. 